\title{
Contribution to the Environmental sustainability by improving the walking behaviour through neighbourhoods' design with special reference to developing countries
}

\author{
Yasmeen $\mathrm{Gul}^{1,{ }^{1}}$, Zahid Sultan ${ }^{2}$, and Gul Ahmed J okhio ${ }^{3}$ \\ ${ }^{1}$ A ssistant Professor, College of A rchitecture and Design, A Ighurair U niversity, Dubai \\ 2 Professor, Civil Engineering, N ew Papua Guinea university, N ew Papua Guinea \\ ${ }^{3}$ A ssistant Professor, Department of civil Engineering, B ritish U niversity in Dubai, Dubai
}

\begin{abstract}
The neighbourhood design (ND) factors such as land-use mix (LUM), street connectivity and housing density have the potential to enhance the walking. A limited number of studies have investigated the association of ND factors with walking in developing countries. Therefore, the objective of this study is to compare the ND factors and investigate their association with walking. The LUM, street connectivity and housing density were measured objectively while walking was calculated subjectively (n-1,042adults). Independent sample t-test and Binary logistic analysis has been used to investigate the comparison and association between ND factors and walking. The results show that two out of three ND indicators are significantly different in both types of neighbourhoods and have positive association with walking Therefore, it can be concluded that, for the sake of walking in developing countries, the neighbourhoods should have mix of different land-uses and well-connected streets rather than sealing the neighbourhoods with walls.
\end{abstract}

\section{Introduction}

Walking is considered good for physical health and the World Health Organization (WHO) has identified that it is important to increase people's levels of walking at neighborhood level. There have been given different guidelines for a human being to be physically active in a given week by different health organizations. The guidelines of WHO for walking are that one should do 30 minutes of walking for 5 days to get 150 minutes or 600 $M E T$, when it is multiplied with its standard MET value which is 4 for walking at moderate level (A insworth, et al. 2000). N ow a days, the association between walking and neighborhood design is gaining attention from researchers of urban and transport planning as well as public health experts. The experts from urban and transport planning conclude that neighborhood design factors such as land-use mix (LUM), street connectivity, and housing density have potential to increase the level of physical activity at neighborhood level (S. Handy 2004, Gul, Sultan and J ohar 2016).

M ixed land-use is a type of urban development where more than one uses from residential, commercial, institutional, recreational and cultural are combined. In these developments, the different land-uses are physically and functionally integrated with each other along with pedestrian connectivity to diverse destinations. In an area with mixed land-use, it is more likely that the majority of trips originating from that area also end there.
Consequently, owing to shorter lengths of these trips, more people walk to their destinations, thus increasing pedestrian activity. Therefore, it is concluded by many researchers that there is a direct relationship between mixed land-use and walking. The relationship between mixed land-use and walking has been widely studied. A few studies have explained that a measure of land-use mix is associated with moderate (walking) level of physical activity (Frank, et al. 2005, Strath, Isaacs and Greenwald 2007, Aytur, Rodriguez, et al. 2007, Gul 2017). A nother study of North Carolina involving more than 6000 participants explained that mixed land-use plans were found positively associated with both leisure and transportation walking (Aytur, Rodriguez, et al. 2008). Various indices are used to calculate LUM ; for example, entropy index, dissimilarity index, and mix type index (Bordoloi et al., 2013). At the same time, street connectivity is defined as "the directness and availability of alternative routes from one point to another within a street network (M edicine, Transportation Research Board/Institute of 2005, Gul, Sultan and J okhio 2018); number of intersections per square kilometer (Frank, et al. 2005); percent of T-intersections and 4-way intersections (S. L. Handy 1996); average block area (K rizek 2003); median block area (A. Forsyth 2006) and number of entrance and exit links (M CN ally and Ryan 1993). Using these local measures, prior research has related higher local street connectivity (Frank, et al. 2005, G reenwald and Boarnet 2000, Boarnet 2000) and smaller blocks (Moudon, et al. 2006) to more walking. Different 
methods have been used to calculate street design such as street network in GIS and Space Syntax to correlate with walking (Baran, Rodri Guez and K hattak 2008). Housing density is a measurement of housing units in an area. While many people use the term density, different countries and even municipalities, as well as different professions, have come up with a wide variety of definitions of density; but housing density is typically defined as the number of dwellings per hectare ( $d w / h a)$

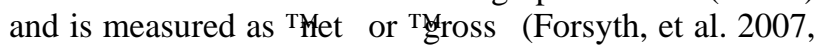
Gul, Sultan, et al. 2019). Different methods have been used to calculate ND such as perceived (Brownson, et al. 2009) and objective (Frank, et al. 2005).

There has emerged a new form of neighborhoods called gated communities and neighborhoods (GC's), which are walled and gated from the rest of the neighborhoods in a city. These neighborhoods have recently emerged and gained popularity around the world among consumers (Blakely and Snyder 1997, Gul, Sultan, et al., Measuring the differences of neighbourhood environment and physical activity in gated and non-gated neighbourhoods in Karachi, Pakistan 2019). There are three main types of $\mathrm{GC}^{\prime} \mathrm{s}$, which include prestigious gated communities, lifestyle gated communities, and security zones gated communities. The main features are aesthetical features, physical activity facilities, and security from crime, respectively, in the three types of gated communities. The trend of gating is growing very fast in developing countries as well and it is has been reported that the GC's in developing countries are combinations of all the three types of gated communities identified above in the USA (B reitung 2012, L eisch 2002, Gul, Sultan, et al. 2018) and have all the features mentioned above. In one study, it is reported that by 2030 most of neighborhoods will be gated in Karachi, Pakistan (A hmad 1993). Therefore, the objectives of this study are to compare the LUM, street connectivity and housing density in gated and non-gated neighborhoods and to investigate the association between these three ND factors with walking in developing countries

\section{Methods}

\subsection{Study Area}

A cross-sectional study was conducted by matching gated neighbourhoods with counterpart non-gated neighbourhoods located in a big metropolitan city of Pakistan. Karachi was selected as the study area because it is one of the largest cities, with a total area of 3,527 km2 ( Pakistan Bureau of Statistics 1998), among Asian developing countries (World Atlas 2017) and has a heterogeneous population (A mer 2013). This study is part of a gated communities physical activity study (GCsPAS). There are two major types of developments in Karachi city: planned and unplanned. The planned development has two more types: single family and multifamily. The multifamily development includes either walk-ups or high-rises up to 16 stories. A new trend in neighborhood development, a gated and guarded neighborhood, is growing fast in Karachi city; it is reported in one study that by 2030 most of the neighborhoods in the city will be gated for the sake of safety and a healthy lifestyle (A hmad 1993). There are six districts, 18 towns, 216 union councils, and four development authorities in the city. The districts are Karachi South, Karachi East, Karachi Central, Karachi West, Malir, and cantonments. The Karachi South and West districts were not included in this study because they have no gated neighborhoods. Four neighborhoods from each development type - single-family gated, multifamily gated, single family non-gated, and multifamily non-gated - were selected, yielding 16 neighborhoods.

The other important factors which were taken into account for selection of neighborhoods were income group, and population density of the neighborhoods. The income group of selected neighborhoods was from the upper-middle to high-income groups (Rs.65,000 to Rs. 250,000 per month, which is approx. $\$ 650 \pm \$ 2,500$ $P M)$. The reason for selecting middle- to high-income neighborhoods was because gated neighborhoods are mostly for middle- to high-income groups; therefore, the counterparts of gated neighborhoods were also selected from the same income groups. The demographics (population density) were the third important attribute for selecting the same neighborhoods, which should have a closer population density. The population density was calculated through the gross housing density multiplied with the average household size of Karachi city ( Pakistan Bureau of Statistics 1998) of each neighborhood. The gross populations of gated and counterpart non-gated neighborhoods were close to each other. The area for each neighborhood was the fourth important factor which was taken into account for selection of these neighborhoods. The area of each neighborhood was selected as close to $1 \mathrm{~km} 2$ as possible, because $1 \mathrm{~km} 2$ has been considered an appropriate area for individuals to access PA F. M ost gated neighborhoods in $\mathrm{K}$ arachi were from 0.5 to $1.5 \mathrm{~km} 2$; therefore, we tried to select blocks of non-gated neighborhoods that were as close as possible. The boundary walls were the limit for gated neighborhoods (area $0.5 \pm 1.5 \mathrm{km2}$ ), and blocks of the same size were selected as non-gated neighborhoods in this study.

\subsection{Study Sample}

Simple random sampling was done by using the Cochran (1963) formula for sample size. The area under normal curve was chosen as 1.96, which corresponds to a $95 \%$ confidence level; the true proportion was chosen as 0.5 , and the acceptable error margin was chosen as $5 \%$, resulting in a value of 0.05 . A ccording to this method, we needed 384 individuals in each of the two types of neighborhoods (gated versus non-gated), i.e. 768 in total. However, we chose an oversampling approach. Seventyfive individuals from each neighborhood, i.e. 1,200 in total, were selected who met the inclusion criteria for this study. The inclusion criteria were (1) being able to read and write Urdu or English, (2) having lived in the 
neighborhood for at least three months, and (3) having no serious impaired ability to do physical activity. The final study population for analysis after exclusion due to missing data consisted of 1,042 individuals. The recruitment process and survey were conducted by trained surveyors. The survey was conducted from January 2016 to June 2016 under the supervision of the first author of this study.

\subsection{Data Collection and Statistical Analysis}

Two types of data were collected for this study; the dependent, and independent variables. The dependent variable was walking. Walking is sum of practical walk and recreational walk, which was calculated through Neighborhood Physical Activity Questionnaire (NPAQ) (Giles-Corti 2005). The questions for walking were the following (1) in last 7 days, did you walk in or around your neighborhood or gated community to get to or from somewhere (such as walking to public transport or shops) (2) The participants were asked to tick all the places where they have walked as a means of transportation and leisure in or around their neighborhood in last 7 days and write the number of return trips as well as time in minutes of one way trip. The minutes were then multiplied with the standard MET value for each type of walking. Standard MET value is 4 for practical walking and 3.5 for recreational walking. The data of walking was then categorized into people getting 0 MET from walking, >600 MET of walking in a week, or <600 MET of walking, according to the guidelines of WHO.

Independent variables, on the other hand, were the three main factors of neighborhood design including land-use mix, street connectivity, and housing density. Data on land-use mix and housing density were delivered by the development authorities in the form of land-use maps and AutoCAD drawings, and were converted into GIS maps. The land use mix was calculated through the entropy index, which determines the evenness of the distribution of the four categories of land use including residential, commercial, recreational and public buildings in a $1 \mathrm{~km} 2$ area of neighborhood under question. The boundary wall was set as the limit for gated neighborhood while blocks of $1 \times 1 \mathrm{~km}$ were selected from non-gated residential areas. The category of public buildings consisted of health and education facilities (Bordoloia, et al. 2013, M anaugh and K reider 2013). The housing density was calculated through gross density from number of housing units per site area in hectares (Forsyth, et al. 2007). Street connectivity, on the other hand, was calculated through Space Syntax (Axial map). Space Syntax, a set of theories and techniques for the analysis of spatial patterns, was conceived by Bill Hillier and colleagues at The Bartlett, University College London in the late 1970 s to early 1980 s as a tool to help urban planners simulate the likely social effects of their designs (Lida and Shinichi 2005). In this system, the spaces in a given neighborhood are broken down into components and analyzed. Space Syntax examines the spatial structure of cities and neighborhoods by first modeling their network of spaces or the land area not designated as buildings, including streets, squares, roads, pedestrian paths, and parks, among other non-built-up areas in a given location (Koohsari, et al. 2014). These space components, also referred to as networks of choice are then represented as maps and graphs describing the relative connectivity and integration between those space components. This system utilizes three basic conceptions of space including visibility graphs, axial maps lines, and convex spaces. Axial maps are used to calculate connectivity. These maps have the longest and fewest lines, called axial lines, that cover all the spaces in a layout and connect them with each other. The axial lines are assumed to be the sight lines for people moving in a spatial network. Axial lines can be drawn either by hand or by using software such as Depthmap $X$ and AJAX etc, which are freely accessible software developed by A lasdair Turner at University College London (Peponis, et al. 1997, Turner, Penn and Hillier 2005, Jiang and Liu 2010). The values can be transferred into statistical and spatial programs e.g., GIS, SPSS \pm for further analysis. These software have been widely used for street connectivity of neighborhoods such as in the study of the differences in the street connectivity in old and new neighborhoods of $M$ alaysian small towns ( $M$ ohamad and Said 2014) and defining and generating axial lines from street center lines for better understanding of urban morphology (Liu and Jiang 2012).The details of calculation methods of the ND indicators are given in Table1.

Table 1. Neighbourhood Design indicators.

\begin{tabular}{|c|c|}
\hline ND Factors & Method \\
\hline LUM & $\begin{array}{c}\text { Entropy = Sum }[P j \times \ln (P j) / / n(J)] \\
\text { where, Pj is the proportion of total } \\
\text { land area of jth land use category } \\
\text { found in the tract being analysed and J } \\
\text { is the total of different land uses } \\
\text { considered in the study area }\end{array}$ \\
\hline Street Connectivity & Space Syntax (A xial map) \\
\hline Housing Density & $\begin{array}{c}\text { Number of D wellings per residential } \\
\text { acre = N umber of dwellings/site area } \\
\text { (in hectares) }\end{array}$ \\
\hline
\end{tabular}

Statistical analysis was done in two parts. Part one explained the group statistics and independent sample ttest of all dependent and independent variables. Part two of statistical analysis between ND factors and walking was done by Binary logistic regression to investigate the association of objectively measured ND factors with walking in developing countries. The ND factors were categorized into quartiles and walking was dichotomized into $<600$ MET of walking per week and $>600$ MET of walking per week:

\section{Results}

\subsection{Descriptive Analysis}


A $n$ independent-samples t-test was conducted to compare land-use mix, street connectivity and housing density as well as walking between gated and non-gated neighborhoods. There was a significant difference in the values of land-use mix, street connectivity, and walking for gated $(M=.42,2.7$ and $434.1, S D=0.15,0.45$, and 490.7) and for non-gated neighborhoods ( $M=0.44$, 3.18and $633.4, S D=0.15,0.62$ and 674.5). The conditions are; $\mathrm{t}(14)=-0.3, \mathrm{p}=0.0001$ for land-use mix, $\mathrm{t}(14)=-1.5$, $p=0.0001$ for street connectivity and for walking the conditions are $\mathrm{t}(631)=-4.2, p=0.0001$. These results suggest that land-use mix, street connectivity and walking are different in both types of neighborhoods and are more in non-gated neighborhoods as compared to gated neighborhoods. On the hand the results of housing density show no significance difference $(p=0.981)$ between both types of neighborhoods because the development type of neighborhood which was used for neighborhood selection was same in both types of neighborhoods as explained in the section of study area. The results of group statistics and independent sample ttest are presented in Tables 2 and 3.

Table 2. Group Statistics of dependent and independent variables.

\begin{tabular}{|c|c|c|c|c|c|}
\hline $\begin{array}{c}\text { Neighbourhoo } \\
\text { ds }\end{array}$ & $\begin{array}{c}\text { Gated/No } \\
\text { n-gated }\end{array}$ & $\begin{array}{c}\text { No } \\
\cdot\end{array}$ & Mean & $\begin{array}{c}\text { Std. } \\
\text { Dev. }\end{array}$ & $\begin{array}{c}\text { Std. } \\
\text { Err. } \\
\text { Mea } \\
\text { n }\end{array}$ \\
\hline Land-use M ix & Gated & 8 & 0.43 & 0.15 & 0.05 \\
\hline $\begin{array}{c}\text { Street } \\
\text { Connectivity }\end{array}$ & Gated & 8 & 2.76 & 0.46 & 0.16 \\
\hline $\begin{array}{c}\text { Housing } \\
\text { Density }\end{array}$ & Non-Gated & 8 & 3.18 & 0.63 & 0.22 \\
\hline & Non-Gated & 8 & 34.59 & $\begin{array}{c}18.85 \\
6.66\end{array}$ \\
\hline W alking & Gated & $\begin{array}{c}33 \\
0\end{array}$ & $\begin{array}{c}434.1 \\
7\end{array}$ & $\begin{array}{c}490.7 \\
5\end{array}$ & 27.02 \\
\hline & Non-Gated & $\begin{array}{c}30 \\
3\end{array}$ & 633.5 & 674.5 & 38.75 \\
8 & \\
\hline
\end{tabular}

Table 3. Independent Sample T-test

\begin{tabular}{|c|c|c|c|c|}
\hline Measure & LUM & $\begin{array}{c}\text { Street } \\
\text { Connectivity }\end{array}$ & $\begin{array}{c}\text { Housing } \\
\text { Density }\end{array}$ & Walking \\
\hline F & 0.226 & 0.846 & 1.44 & 13.23 \\
\hline Sig & 0.0 & 0.0 & 0.02 & 0.0 \\
\hline t & 0.31 & 1.54 & 0.024 & 4.27 \\
\hline df & 14 & 14 & 14 & 631 \\
\hline Sig (2-tailed) & 0.761 & 0.145 & 0.981 & 0.0 \\
\hline M ean Diff & 0.024 & -0.42 & -0.3 & 199.32 \\
\hline
\end{tabular}

\begin{tabular}{|c|c|c|c|c|}
\hline Std. Err. Diff & 0.076 & 0.275 & 12.59 & 46.62 \\
\hline $95 \%$ & - & -1.015 to & -27.3 to & 290.88 \\
$\begin{array}{c}\text { Confidence } \\
\text { Interval of the } \\
\text { Difference }\end{array}$ & $\begin{array}{c}0.019 \\
\text { to } \\
0.14\end{array}$ & 0.165 & 26.7 & to \\
\end{tabular}

\subsection{Association between ND indicators and walking}

A binary logistic model has been developed to investigate the association between Neighborhood Design (ND) factors and walking. The ND factors were treated as independent variables while walking was treated as the dependent variable in this study. The ND factors were categorized into quartiles while walking was dichotomized into $>600$ MET of walking per week and $<600$ MET of walking per week. The land-use mix was calculated through entropy index as discussed in the methods section, on a scale of $0-1$. The number 1 shows a perfect mix of residential, commercial, recreational and public buildings in a $1 \mathrm{Km} 2$ neighborhood area while 0 show least mix of four land-uses. The land-use values were then normalized form 1-10. Later land-use mix was divided into quartiles of very low to very high with the values of (min-1.07-max-6.71) for logistic regression analysis. Street connectivity was calculated through the Space Syntax (Axial map) method, which provided three attribute values for each neighborhood; low, average and maximum. This study used the average attribute values of connectivity. Street connectivity was also categorized into very low to very high quartiles with the values of (min-2.10-max-4.29). The housing density was calculated through gross density where the number of houses was calculated in one hectare area. Housing density was also categorized in to four quartiles of very low to very high number of dwellings in $1 \mathrm{Km} 2$ neighborhood area (min12- max-96). The categorical results of binary logistic regression in Table 3 show that there is a statistically significant association between land-use mix, street connectivity, and housing density, with walking. The walking increases 1.5 and 1.8 times in quartile 2 and 3 of land-use mix than the reference quartile (lowest quartile) with the $p=0.007$ and 0.0001 , respectively. At the same time, the walking increases 1.3 and 2.1 times in quartile 3 and 4 of street connectivity than reference quartile (lowest quartile) with significant $p$-values of 0.001 and 0.006 , respectively. On the other hand, housing density has significant negative association with walking with 0.3 and 0.1 times in quartiles 3 and 4 than reference quartile (lowest quartile) of housing density, which means less people, get $>600$ MET of walking in a week through walking when there is increase in housing density in $\mathrm{K}$ arachi. This indicates the probability that increasing of housing density in $\mathrm{K}$ arachi increases the commercial activities and number of people in streets, which makes the street uncomfortable for walking. The correction percentage of model is $80 \%$, while the -2 log likelihood ratio is 943 . The Nagelkerke $\mathrm{R}$ Square is $11 \%$. The results of association of categorical neighborhood design factors with categorical walking as well the model reliability are presented in Table 4. 
Table 4. Independent Sample T-test

\begin{tabular}{|c|c|c|c|c|c|}
\hline & B & S.E. & Wald & Sig & $\operatorname{Exp}(B)$ \\
\hline \multicolumn{6}{|l|}{ LUM } \\
\hline \multicolumn{6}{|l|}{$\begin{array}{c}\text { Q1 (very } \\
\text { low 1.07- } \\
3.77 \text { ) }\end{array}$} \\
\hline $\begin{array}{c}\text { Q2 (low } \\
3.81-4.06)\end{array}$ & 0.456 & 0.17 & 7.17 & 0.007 & 1.577 \\
\hline $\begin{array}{c}\text { Q3 (high } \\
4.37-5.54 \text { ) }\end{array}$ & 0.63 & 0.17 & 13.65 & 0.0 & 1.878 \\
\hline $\begin{array}{c}\text { Q4 (very } \\
\text { high 5.71- } \\
6.71 \text { ) }\end{array}$ & & & 43.204 & 0.0 & 1.363 \\
\hline \multicolumn{6}{|c|}{ Street Connectivity } \\
\hline \multicolumn{6}{|l|}{$\begin{array}{l}\text { Q1 (very } \\
\text { low 2.1- } \\
2.54 \text { ) }\end{array}$} \\
\hline $\begin{array}{l}\text { Q2 (low } \\
2.55-3 \text { ) }\end{array}$ & 0.049 & 0.396 & 0.015 & 0.902 & 1.05 \\
\hline $\begin{array}{l}\text { Q3 (high } \\
3.04-3.24 \text { ) }\end{array}$ & 0.755 & 0.276 & 7.49 & 0.06 & 2.13 \\
\hline \multicolumn{6}{|c|}{ Housing Density } \\
\hline $\begin{array}{c}\text { Q1 (V ery } \\
\text { low 12-18) }\end{array}$ & & & 22.42 & 0.0 & \\
\hline $\begin{array}{c}\text { Q2 (low 24- } \\
37 \text { ) }\end{array}$ & 0.645 & 0.282 & 5.227 & 0.022 & 0.524 \\
\hline $\begin{array}{l}\text { Q3 (high 45- } \\
51 \text { ) }\end{array}$ & $\overline{-}$ & 0.289 & 12.057 & 0.001 & 0.367 \\
\hline $\begin{array}{c}\text { Q4 (very } \\
\text { high 64-96) }\end{array}$ & $\overline{-}$ & 0.386 & 2.96 & 0.085 & 0.514 \\
\hline \multicolumn{5}{|l|}{ Omnibus test } & 0.0 \\
\hline \multicolumn{5}{|c|}{-2 log likelihood } & 943.735 \\
\hline \multicolumn{5}{|c|}{ Nagelkerke R Square } & 0.113 \\
\hline \multicolumn{5}{|c|}{ Hosmer and L emeshow test } & 1.0 \\
\hline \multicolumn{5}{|c|}{ Percentage of correction $80 \%$} & \\
\hline
\end{tabular}

\section{Discussion and conclusion}

The results of land-use mix, street connectivity and housing density with walking show that there is a significant association between the ND factors and walking in developing countries. The results of land-use mix, and street connectivity have positive association with walking while housing density has negative association with walking. The results of land-use mix and street connectivity are in agreement with the previous research in developed countries but the housing density has contrasting results with previous results from developed countries. The result of land-use mix and street connectivity agree with the previous research of Frank, et al. (2005). Based on the their findings the land-use mix, connectivity of streets, and housing density have positive relationship in bivariate analyses; the results of the present study show that land-use mix and street connectivity have positive relationship with walking, but housing density has negative association. The reason for negative association of housing density with walking is that $\mathrm{K}$ arachi is a populated city and increase in housing density also increases the commercial activities, crowded streets, as well as fear of crime. Thus the findings that people living in mixed land-use and better connected neighborhoods are more likely to be active enough to achieve health benefits have great policy significance, and are consistent with the results of (Kockelman and Cervero 1997).

The results of comparison of ND indicators in gated and non-gated neighborhoods show that street connectivity and land-use mix are significantly different in both types of neighborhoods and this result is consistent with the previous research that gated neighborhoods are less connected, therefore, less walk able than surrounding neighborhoods (B urke and Sebaly 2001, Miao 2003). The researchers reported that the streets of gated neighborhoods inside and near boundary walls are less connected therefore less walk-able and lively. According to Miao (2003) when there is no connection between the internal streets to arterial streets, there will be no walking and streets will be deserted. The results on the other hand for housing density are in contrast with the previous studies of Frank et al. (2005). The reason for contrasting results with Frank et al. (2005) can be the use of method as this study has selected same development types of neighborhoods. The second reason for this contrasting result can be that Frank et al., (2005) conducted their research in 13 counties in the US, while this study has been conducted in a developing country where population density is very high as compared to developed areas. Thus the result of this study suggests that two factors of ND, the land-use mix and street connectivity, are important to increase walking while increasing the housing density affects negatively the walking of individuals at neighborhood level.

Strengths of this study are that it is the first study in $K$ arachi, Pakistan having large study sample size, which makes it one of the largest studies so far using objective measures of the neighborhood design. The objective method for calculation of neighborhood design can provide recommendations to policy makers for future neighborhood designs in developing countries such as $\mathrm{K}$ arachi. Limitations of this study are that as it is a crosssectional one-time study, therefore, different effects of the different times of the year couldn't be reported. The second limitation was the use of subjective methods for calculating walking. This study was conducted in a populated city of a developing country where the overall perception of crime and fear of strangers is quite high as discussed by Gul et, al. (2018); therefore, people were reluctant to provide data. These issues may limit generalizability of the findings of this study.

Present results indicate that people are more likely to meet recommendations of $600 \mathrm{M} \mathrm{ET}$ in a week when they live in neighborhoods with mixed land-use and street connections of residential areas to other types of land uses such as commercial, recreational, or public buildings. 
Neighborhood design factors especially the land-use mix and street connectivity were significantly related to walking at neighborhood level. On the other hand, the results show that there is negative association of housing density with walking in developing countries. Therefore, the results of this study highlight that the neighborhood should have more land-use mix and street connectivity the associated problems should be investigated and improved for making neighborhoods as physically active as possible in developing countries

\section{References}

1. Pakistan Bureau of Statistics. 1998. Population size and growth of major cities. Karachi: Pakistan Bureau of Statistics.

2. A hmad, Nuzhat. 1993. "Choice of Neighbourhoods by Mover Households in Karachi." U rban Studies 1257-1270.

3. A hmad, Nuzhat. 1993. "Choice of Neighbourhoods by Mover Households in Karachi." U rban Studies 30 (7): 1257-1270.

4. Ainsworth, Barbara E, W illiam L H askell, M elicia C Whitt, Melinda L Irwin, Ann M Swartz, Scott J Strath, William L O 0 rien, et al. 2000. "Compendium of physical activities: an update of activity codes and MET intensities." Medicine and Science in Sports and Exercise 32 (9): 498-504.

5. A mer, K hawaja. 2013. Population explosion: Put an embargo on industrialisation in $\mathrm{K}$ arachi. October 06. A ccessed J anuary 17, 2014. http://tribune.com.pk.

6. Aytur, Semra A, Daniel A Rodriguez, Kelly R Evenson, Diane J Catellier, and Wayne D Rosamond. 2007. "Promoting Active Community Environments Through Land Use and Transportation." A merican Journal of Health Promotion 21 (4): 397-407.

7. Aytur, Semra A, Daniel A Rodriguez, Kelly R Evenson, Diane J Catellier, and Wayne D Rosamond. 2008. "The sociodemographics of land use planning: Relationships to physical activity, accessibility, and equity." Health \& Place 14: 367385.

8. Baran, Perver K, Danial A Rodri Guez, and A sad J K hattak. 2008. "Space Syntax and Walking in a New Urbanist and Suburban Neighbourhoods." J ournal of U rban D esign V ol. 13. N o. 1, 5+28.

9. Blakely, Edward J, and Mary G Snyder. 1997. "Divided We Fall: Gated and Walled Communities in the United States." In A rchitecture of Fear, by Edward J Blakely and Mary G Snyder, edited by $\mathrm{N}$ an Ellin. N ew Y ork: Princeton A rchitectural Press.

10. B oarnet, M. G. \& Greenwald, M. J . 2000. " L and use, urban design, and nonwork travel: reproducing other urban areas' empirical test results in Portland, Oregon." Transportation Research Record 1722, pp. $27 \pm 37$.

11. Bordoloia, Pupjyoti, A mit Motea, Partha Pratim Sarkarb, and C M allikarjuna. 2013. "Quantification of Land Use Diversity in The Context of Mixed Land Use." Procedia - Social and Behavioral Sciences 563-572.

12. B reitung, Werner. 2012. "Enclave Urbanism in China: Attitudes Towards Gated Communities in Guangzhou." U rban Geography 33 (2): 278-294.

13. Brownson, R C, C M Hoehner, F Day, A Forsyth, and J F Sallis. 2009. "M easuring the built environment for physical activity: state of the science." A m J Prev M ed 36:S99+123 el12.

14. Burke, Matthew, and Christian Sebaly. 2001. "L ocking in the pedestrian? The privatised streets of gated communities." World Transport Policy \& Practice 7 (4): 61-66.

15. Forsyth, A. 2006. "Twin Cities Walking Study: Environment and Physical Activity: " GIS Protocols, Version 4.0. Available at http://www.designcenter.umn.edu/projects/current/h ealth/ epaGISprotocols.html.

16. Forsyth, A nn J, Michael Oakes, Kathryn H Schmitz, and $M$ ary Hearst. 2007. "Does Residential Density Increase Walking and Other Physical Activity?" U rban Studies 679-697.

17. Frank, Lawrence $D$, Thomas $L$ Schmid, James $F$ Sallis, James Chapman, and Brian E Saelens. 2005. "Linking Objectively Measured Physical Activity with Objectively Measured U rban Form: Findings from SMARTRAQ." American Journal of Preventive M edicine 28 (2): 117-125.

18. Giles-Corti, B., Timperio, A., Bull, F., \& Pikora, T. 2005. "Understanding physical activity environmental correlates: increased specificity for ecological models. Exercise and Sport Sciences Reviews." Exercise and Sport Sciences Reviews 33(4), 175e181.

19. Greenwald, M J, and M G Boarnet. 2000. "Built environment as determinant of walking behavior: analyzing nonwork pedestrian travel in Portland, Oregon." Transportation Research Record 1780, pp. $33 \pm 42$.

20. Gul, Yasmeen. 2017. "EFFECTS OF NEIGHBOURHOOD ENVIRONMENT ON PHYSICAL ACTIVITIES IN GATED AND NONGATED NEIGHBOURHOODS IN KARACHI, PAKISTAN." Thesis. Johar Bahru: University Technology M alaysia, October.

21. Gul, Y asmeen, Zahid Sultan, and F oziah J ohar. 2016. "Effects of Neighborhood's built environment on physical activities in gated communities: a review." International Journal of Built Environment and Sustainability 1-21.

22. Gul, Y asmeen, Zahid Sultan, and Gul A hmed Jokhio. 2018. "The association between the perception of crime and walking in gated and non-gated neighbourhoods of Asian developing countries." Heliyon 715.

23. Gul, Y asmeen, Zahid Sultan, M ehdi Moeinaddini, and Gul Ahmed Jokhio. 2019. "M easuring the 
differences of neighbourhood environment and physical activity in gated and non-gated neighbourhoods in Karachi, Pakistan." Journal of U rban Design 494-513.

24. Gul, Y asmeen, Zahid Sultan, M ehdi M oeinaddini, and Gul Ahmed Jokhio. 2018. "The effects of physical activity facilities on vigorous physical activity in gated and non-gated neighborhoods." L and use policy 155-162.

25. Gul, Y asmeen, Zahid Sultan, M ehdi M oeinaddini, and Gul A hmed J okhio. 2019. "The effects of sociodemographic factors on physical activity in gated and non-gated neighbourhoods in Karachi, Pakistan." Sport in Society 1225-1239.

26. Handy, S. L. 1996. "Urban form and pedestrian choices: study of Austin neighborhoods, ,." Transportation R esearch Record 1552, pp. 135 +144.

27. Handy, Susan. 2004. "Community Design and Physical A ctivity: What Do We Know? \pm and what DON'T we know." University of California Davis.

28. Hillier B, Hanson J. 1984. "The Social Logic of Space." Cambridge: Cambridge UniversityPress.

29. Jiang, Bin, and Xintao Liu. 2010. "Automatic generation of the axial lines of urban environments to capture what we perceive." International Journal of Geographical Information Science Volume 24, Issue 4.

30. Kockelman, Robert, and Kara Cervero. 1997. "Travel Demand And The 3ds : Density, Design And Diversity." ransportation Research Part D: Transport and Environment 199-219.

31. K oohsari, M ohammad Javad, A ndrew T K aczynski, Gavin R M cormack, and Takemi Sugiyama. 2014. "Using Space Syntax to Assess the Built Environment for Physical Activity: A pplications to Research on Parks and Public Open Spaces." L eisure Sciences 206-216.

32. Krizek, K. J. 2003. "Residential relocation and change in urban travel: does neighborhood-scale urban form matter?" Journal of the American Planning A ssociation, 69(3), pp. 265 \pm 279 . .

33. Leisch, Harald. 2002. "Gated communities in Indonesia." Cities 19 (5): 341-350.

34. Lida, Bill Hillier, and Shinichi. 2005. "N etwork and Psychological Effects in Urban Movement." Network and Psychological Effects in Urban M ovement $475 \pm 490$.

35. Liu, Xintao, and Bin Jiang. 2012. "D efining and generating axial lines from street center lines for betterunderstanding of urban morphologies." International Journal of Geographical Information Science 26(8) 1521+1532.
36. M anaugh, K evin, and Tyler K reider. 2013. "W hat is mixed use? Presenting an interaction method for measuring land use mix." J ournal of Transport and Land U se 6(63-72).

37. MCNally, M G, and S Ryan. 1993. "Comparative assessment of travel characteristics for neotraditional designs,." Transportation Research Record, 1400, pp. $67 \pm 77$.

38. Medicine, Transportation Research B oard/Institute of. 2005. Does the Built Environment Influence Physical Activity? Examining the Evidence,. TRB Special Report, 282.

39. Miao, Pu. 2003. "Deserted Streets in a Jammed Town: The Gated Community in Chinese Cities and Its Solution." J ournal of U rban Design 8 (1): 45-66.

40. M ohamad, W an Saiful Nizam Wan, and Ismail Said. 2014. "Differences of street connectivity between old and new zone in Malaysian small town." International Alliance for Sustainable Urbanization and Regeneration. 501-510.

41. Moudon, A V, C Lee, A D Cheadle, Garvin C, D Johnson, T L Schmid, R W eathers, and L Lin. 2006. "Operational definitions of walkable neighborhood: theoretical and empirical insights." Journal of Physical A ctivity and Health 3(Sup. 1), pp. S99.

42. 2016 NationsOnline.org. http://www.nationsonline.org/oneworld/bigcities.ht $\mathrm{m}$.

43. Organization, World Health. 2010. Global Recommendations on Physical A ctivity for Health. W HO Library Catal oguing-in-Publication Data.

44. Peponis, John, Jean Wineman, M ahbub Rashid, S Kim, and Sonit Bafna. 1997. "On the Generation of Linear Representations of Spatial Configuration." $S$ PACE SYNTAX FIRST I NTERNATIONAL SYMPOSIUM . LONDON .

45. Strath, Scott, Raymond Isaacs, and Michael J Greenwald. 2007. "Operationalizing Environmental Indicators for Physical Activity in Older Adults." J A ging Phys A ct. 15 (4): 412-424.

46. Turner, Alasdair, Alan Penn, and Bill Hillier. 2005. "An Algorithmic Definition of the Axial Map." Environment and Planning B: Urban A nalytics and City Science V ol 32, Issue 3.

47. World Atlas. 2017. Populations of 150 Largest Cities In The World. Groningen: University of Groningen. Accessed June 2, 2016. http://www.worldatlas.com/citypops.htm. 